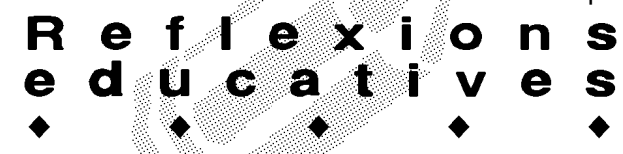

\title{
ALLÀ D'ON VÉNEN ELS CONTES
}

\author{
M. Àngels Ollé Romeu. Àrea de Didàctica de la Llengua i la Literatura. URV
}

\section{Els contes que expliquem avui}

Explicar històries, contes, rondalles, etc. és un dels costums que els humans compartim des que el món és món, o sia, des que els homes parlen. Compartim el costum i també les mateixes històries.

Però del fet de compartir les mateixes històries, no en tenim gaire consciència. La majoria de contes que encara avui s'expliquen a casa o a l'escola s'han conservat oralment com un patrimoni familiar, no tenen un autor conegut ni data de creació, i generalment es prenen per autors els recopiladors com Perrault, el germans Grimm, etc.

El pas del temps i l'ús de tantes generacions han anat polint i variant detalls, de manera que no és gens estrany trobar diverses versions d'un mateix conte 0 trobar clares coincidències entre contes de llocs i cultures molt llunyanes. Els contes populars tenen l'inconvenient de no sorprendre'ns en l'esquema de la narració -inici, marc estable, trencament del marc estable, conflicte, mecanismes de correcció, retorn al marc estable (ROS, 1989)- però sortosament acostumen a portar nous detalls que ens fan interessar per la resolució del conflicte.

Els contes de tradició oral tenen el do de la mal.leabilitat a la boca de cada narrador o narradora, i aquest fet els permet mantenir una vital actualitat que queda ben demostrada per noves variants que es van incorporant amb els anys (l'armari on s'amaga l'àvia de la Caputxeta Vermella, etc.) així com noves servituds didàctiques (contes per pensar, contes de valors, etc.) que justifiquen el seu ús des d'una perspectiva utilitària cada vegada més restrictiva. Ha estat l'interès que tenen els nens pels contes el que ha portat pares i mestres a oblidar la intencionalitat educativa i formadora i substituirla per un objectiu didàctic puntual, que ha restringit en molts casos no solament la seva qualitat literària, sinó també l'abundància de matisos i missatges que en diferents plans ens aporten la majoria de contes populars.

Així ens trobem que han proliferat els reculls de contes d'arreu del món, amb una tria de narracions de diverses cultures amb l'objectiu d'ajudar en la construcció de valors de convivència, com pot ser la interculturalitat. S'espera d'aquests contes que aportin informació sobre altres cultures de manera que aquest coneixement ajudi en l'acolliment dels nouvinguts, però algunes vegades aquests mateixos alumnes desconeixen les llegendes pròpies, com ara la del Pont de Diable de Tarragona. Curiosament en alguns d'aquests reculls de contes d'altres països ens trobem amb certes similituds amb històries conegudes, com ara El conte de la lletera, El millor pretendent del món, etc.

Si volem saber la raó d'aquestes semblances, hem de buscar les arrels, hem d'anar allà d'on vénen els contes, i aquestes vénen d'una de les cultures més antigues que coneixem, la cultura índia. Aquesta cultura té un llibre de contes, el Panxatantra, que junt amb el Mahabharata i el Ramayana, formen el conjunt d'obres més antigues de la literatura universal.

\section{PANTXATANTRA}

\section{FAULES DE VISNU SHARMA}

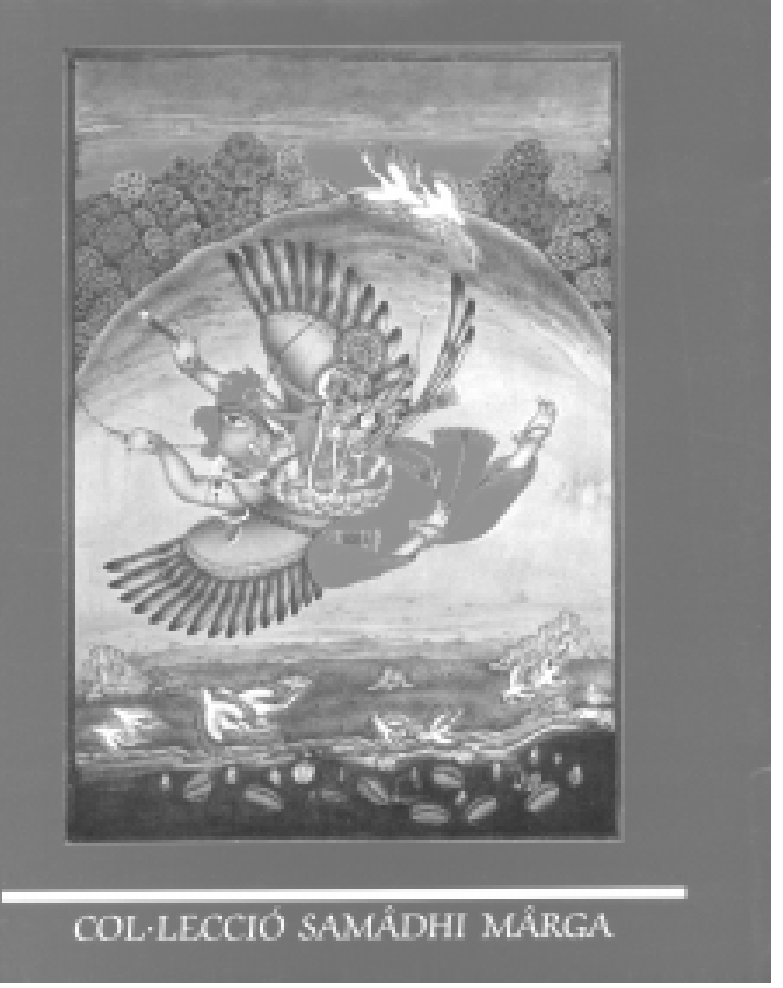




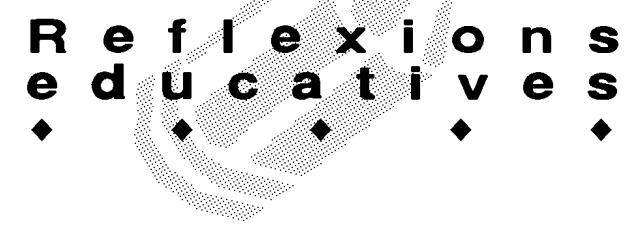

\section{Les seves arrels}

El Panxatranta és una col-lecció de cinc llibres que contenen uns setanta contes, aforismes i versets; el text està escrit en sànscrit per Visnu Aharna en els segles III-II a C. L'obra és el conjunt d'històries que va crear un ancià braman versat en totes les ciències, quan va acceptar ser el preceptor dels tres fills del rei. El repte a tothom semblava insuperable, ja que els prínceps eren, segons el mateix rei, ignorants i no tenien cap interès pels estudis. El recurs didàctic del vell mestre va ser la narració d'històries, la majoria amb protagonistes animals, amb situacions versemblants en la vida dels humans.

El Panxatantra consta de cinc llibres:

1. Desunir amics.

2. Adquirir amics.

3. La guerra de les cornelles i les òlibes.

4. Perdre el que ja s'havia guanyat.

5. Actuar sense reflexionar.

Cada títol conté una sèrie d'històries on les bèsties parlen, el monjos somnien i els poderosos són mal aconsellats. Les narracions estan ben lligades, de manera que la resolució del conflicte introdueix la història següent, on s'exemplifica el consell del conte anterior. Aquesta tècnica és, segons Josep M. Duch (2003), com si les narracions seguissin el principi hindú dels cercles que menen cap a un camí interior; les narracions segueixen l'estructura concèntrica dels mandala.

Les narracions utilitzen dos registres: la descripció en prosa per als fets i el vers per a les reflexions morals que sorgeixen de cada fet. El resultat és un conjunt de peces literàries amb molts matisos morals i recursos expressius, que exigeixen una lectura atenta i reposada.

El vell braman educa els fills del rei no amb la memorització de normes morals, principis ètics, etc., sinó amb la narració d'històries on els valors i normes justifiquen el comportament dels protagonistes, de manera que al projectarse els oients en els protagonistes de les històries interioritzaran també els principis morals que aquestes contenen.

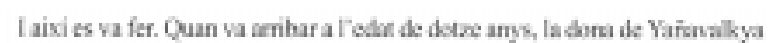

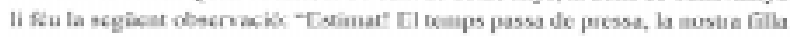
ja ha amibat a l'edat per casar-se; per tank, pensa-ki geriosament"

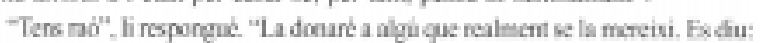

Car, si la noi hi cta dacord, invocare el Sol i thi donare"

"Si, fes-bo!", repoergue la seva duna.

Amb els seus poders inwed el Sel. Aquest va spareixer de seguida i li pregunti: "Mobinis!" Per qué m' 'has cridat?"

"Aquesta és la mexa filla!", respongué Yañasalkyz. "Si es wol caster amb tii, et prezo que acoepes la seva mi".

Seguidament, preguntì a la seva filla "Mcceptes per marit el déu del Sol, que amb els seus rejes it-lumina els tres mons?

"Parel", respongue la noia. "Es maxsa fogos, no vill casar-m'hi. Buscame'n un altere de milleer?
I precisament és aquest plantejament el que se seguirà en generacions posteriors, tant pel que fa a les històries del Panxatantra com pel que fa a la seva metodologia. Avui parlem de faules, paràboles, exemples o contes d'autoajuda, tot plegat variants del mateix recurs: educar, ajudar a créixer a partir d'històries.

Una de les altres característiques del Panxatantra és la utilització dels animals com a protagonistes d'històries humanes; el recurs de projectar els conflictes humans en el món animal ens dóna la possibilitat d'assenyalar comportaments humans negatius amb una certa distància, de manera que es pugui parlar amb més llibertat de febleses sense la por d'estigmatitzar els humans. Segurament la idiosincràsia hindú, el respecte, la veneració pels animals va permetre crear un món fabulós, on les bèsties senten, parlen, raonen i odien com els homes.

Aquests dos recursos, les històries com a educadores $i$ els animals protagonistes, han donat en la literatura universal el nom a un gènere literari, les faules. Tots recordem noms com els d'Isop, La Fontaine, Samaniego, etc. que són fills d'aquesta literatura; com hem dit abans, en el Panxatantra trobem el precedent de la famosa faula de la lletera, i també en aquests contes es troben les arrels del Llibre de les bèsties, de Ramon Llull i les de La disputa de l'ase d'Anselm Turmeda.

\section{Actualització i canvis}

En els reculls contemporanis de contes per a infants, com el de la Sara C. Bryant, trobem El millor pretendent del món, que correspon a La història del ratolí femella,

Quan va arribar l'hora de casar-la no volien de cap manera que es castés amb un princep ratoli, $i$ van declarar que nómés ačceptarieñ per gendre el personatge més poderós del món. I com que aquuest perrsonatge no es presentava ni sabien qui era, el rei Rató se'n va anar a trobar el seu oncle: un ratolí molt saberut que bavia ratat molts pergamins. L'oncle If va dir que el personatge més poderós del món era el Sol, perqué sense el Sol l'arròs no podria madurar. Així és que el rei Rató es va posar en camí per anar a trobar el Sol. Es va enfilar a la muntanya més alta, es va emparrar per l'arc de Sant Marti i, a la fi, va anar a parar a la cova de ponent on el Sol descansava.

-Qué vols germanet? - va dir el Sol, tot bonals, quan el va veure.

-Vine - va dir el rei Rató, amb gran cerimòniaa oferir-vos la mà de la meva filla, la princesa Ratolina, perquè vós sou el personatge més poderós del món î no hỉ ha ningú més que siğui digne d'ella.

-Ha. ha, ha! -va riure el bonatxas del Sol, tot fent l'ullet-Si és així, t'estimo l'atenció, germanet; però no puc acceptar-la. El Núvol és més poderós que jo, perquè quan vol em tapa i no puc brillar. 


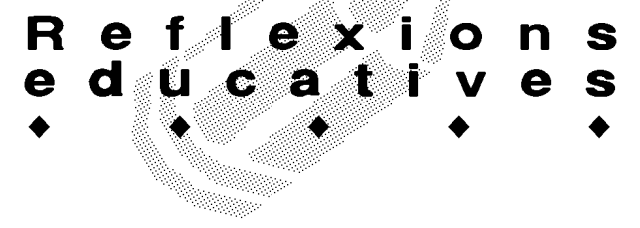

del Panxatantra; també el conte japonès, adaptat per $\mathrm{M}$. Desclot, El pobre pop, correspon a la primera narració del llibre, Perdre o guanyar, i la història del braman i la mangosta que va recollir $\mathrm{R}$. Kipling amb el nom de Rikkitikki-tavi.

Se suposa que amb l'extensió del budisme per l'Àsia les històries del Panxatranta van fer camí cap al nord i van entrar al Nepal, el Tibet i la Xina, i d'allà van anar cap a l'est, cap al Japó, i a l'oest, cap a Mongòlia i Rússia. Hi ha un camí més documentat històricament, que correspon a la traducció del Panxatantra a la llengua pahlavi, ordenada per un rei persa els anys 531-579, i com aquest text després va ser traduït a l'àrab amb el nom de Calila i Dimna. Posteriorment aquest llibre va ser traduït a l'hebreu, al grec, al llatí i a diverses llengües romàniques.

Evidentment un itinerari tan complex en l'espai i en el temps ha deixat molts senyals en les narracions; així, els diversos narradors, traductors i adaptadors han fet canvis segons les pròpies cultures, religions i contextos històrics. En una primera aproximació, els canvis que criden l'atenció en aquests tres contes es refereixen als fets següents:

a) En la història del pare somiatruites de Somasharma. La lletera:

1) Canvi del sexe dels protagonistes: home-dona.

2) Hàbits alimentaris: farina i mantega-llet.

3) Es manté l'actitud somniadora dels protagonistes.

b) En la història del ratolí femella. El millor pretendent del món:

1) Canvi dels protagonistes: savi, dona, filla-un únic protagonista, el rei rató.

c) En la història del mico i el cocodril. El pobre pop:

1) Canvi de la identitat del protagonista cocodril per un drac.

2) S'afegeix un nou personatge, el pop, on es descriu l'origen de la seva naturalesa física.

El canvi dels protagonistes pot ser degut a l'adequació de la història a la realitat del temps en què era explicada; un sadhu hindú no tenia el mateix poder evocador que una lletera a la França del segle XVIII. Cal dir que ara l'ofici en desús és el de la lletera, i que segurament algun contacontes el substituirà per un ofici més actual (esperem que el paper de somiatruites no torni a recaure en una dona).

No cal dir que les adequacions recullen actituds, creences del grup on són explicades; així el silenci de la filla de rei rató solament es pot interpretar com el resultat d'una actitud misògina de certes cultures.

Hem pogut comprovar que els contes ens vénen de molt lluny, però també com els contes, les històries han sofert canvis no pas fortuïts, perquè des de sempre els homes han sentit la necessitat d'aprendre, i aquesta necessitat va lligada amb la possibilitat d'entendre, i per tant els narradors i narradores han refet els contes de manera que fossin més comprensibles i més propers.

Però la vertadera naturalesa dels contes va molt més enllà de les utilitzacions didàctiques massa concretes. Els contes, per curts que siguin, són el resultat d'una formulació de valors morals, estètics, lingüístics,

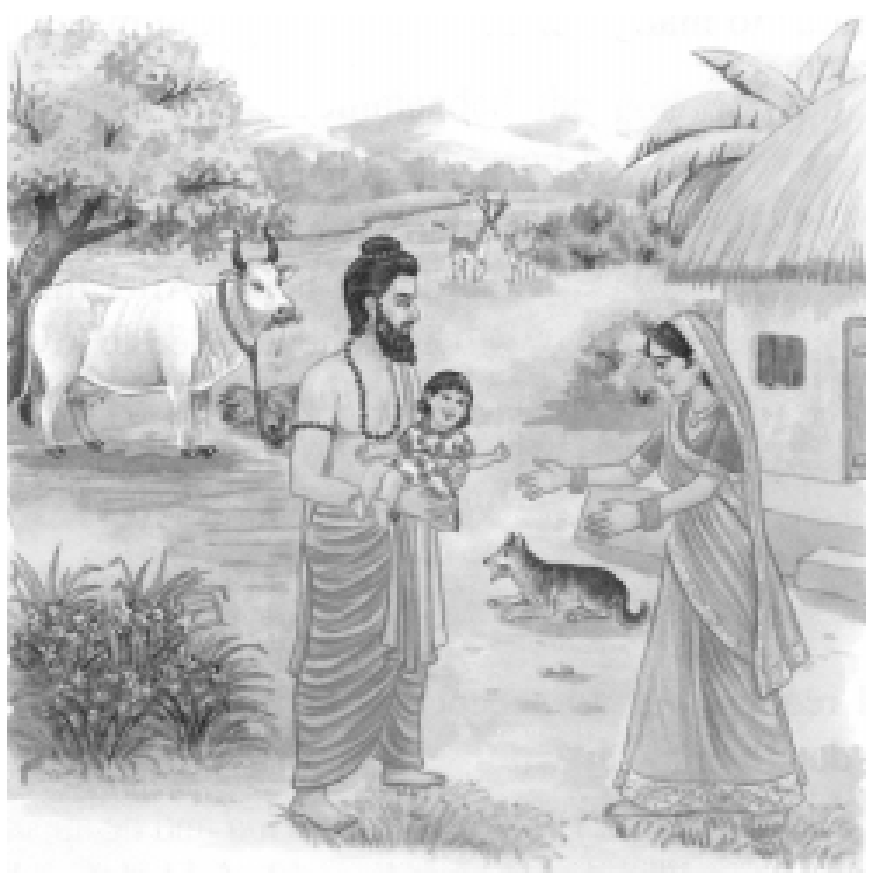

Història del ratolí femella

patrimonials, i normalment tot això va junt, i també s'interioritza conjuntament. Aquesta pot ser la justificació de la pervivència dels contes del Panxatantra. Han estat model, en el fons i en la forma, han nodrit els nostres escriptors, i de manera conscient o no el nostre imaginari col-lectiu. Solament les obres d'art arriben a tenir aquesta transcendència. Segurament té raó Sara C. Bryant (1967) quan diu que els contes són una obra d'art.

\section{Referències bibliogràfiques}

ROS, ROSER. El conte a parvulari. Monogràfic de Llenguatge. Edit. Departament d'Ensenyament. Barcelona. 1989.

DUC, JOSEP M. Panxatantra. Dalmau Editor. Barcelona. 2003.

BRYANT, SARA C. Com explicar contes. Edit. Nova Terra. Barcelona. 1967. 